\title{
RENATA PALLOTTINI: UMA POÉTICA EM LUTA CONTRA ESPAÇOS ASFIXIANTES
}

Kátia da Costa Bezerra*

\section{A}

implantação da ditadura militar no Brasil em 1964 fez com que muitos movimentos reivindicatórios tivessem que restringir sua atuação aos bastidores, só retornando a uma luta mais efetiva nos meados dos anos setenta, quando se inicia um lento processo de abertura política. Assim, embora no final dos anos sessenta já existisse uma maior articulação de grupos voltados para a questão da homossexualidade, somente a partir dos meados da década seguinte começam a surgir, em número cada vez mais expressivo e atuante, publicações e grupos preocupados em construir novas formas de representação.

Contudo, a luta desses grupos por uma maior visibilidade e espaço de atuação sempre foi cercada por um forte sentimento de homofobia por parte da sociedade brasileira de um modo geral. Uma barreira que fez com que os movimentos homossexuais no início fossem compostos por homens e mulheres que procuravam legitimar suas reivindicações através da aliança com outros movimentos minoritários (MacRae, 1990). Constituíam-se em grupos de reflexão que tentavam ajudar seus integrantes a construírem uma identidade mais "positiva", contrapondo-se a estereótipos que os aprisionavam a imagens que os caracterizavam como seres anormais e doentios. Todavia, a tentativa de

* Recém-doutora na Universidade Federal de Minas Gerais. 
BEZERRA, K. C. Renata Pallottini: uma poćtica $\mathrm{cm}$ luta...

construção de uma agenda política única, vista como uma forma de fortalecimento do grupo, é apontada por MacRae como um dos fatores que provocou a fragmentação e o pouco tempo de vida de muitos destes grupos mistos.'

Nesse sentido, as divergências quanto às prioridades, tal como a não aceitação de posicionamentos que não levassem em consideração as questões de gênero, fez com que aos poucos muitas mulheres abandonassem grupos como o SOMOS, criando seus próprios grupos. Estes, constituídos normalmente por um pequeno e sempre instável número de ativistas, tinham por objetivo dar amparo emocional e conscientizar as mulheres que frequientavam os guetos lésbicos sobre a importância de um maior ativismo.

Além disso, a instauração de uma atitude mais receptiva por parte de grupos feministas fez com que muitas ativistas lésbicas se integrassem a seus quadros. Em realidade, a maior aproximação entre esses dois grupos decorreu do fato de seus membros compartilharem de muitos pontos em comum como a preocupação com a saúde, a questão da violência contra a mulher e de sua inserção no campo de trabalho. É importante ressaltar que a presença dessas ativistas forçou o movimento feminista a dar mais atenção à questão da sexualidade e, mais especificamente, ao homoerotismo. Entretanto, o convívio entre elas foi sempre tenso ora pela divergência quanto aos objetivos do movimento, ora pelo constrangimento que a aliança causava quando as feministas heterossexuais tinham que procurar o apoio da Igreja, que repudiava qualquer aliança com os grupos lésbicos. ${ }^{2}$ No entanto, apesar dessas tensões, o Grupo AÇÃO LÉSBICA-FEMINISTA (GALF), mais conhecido como Grupo Lésbica-Feminista (LF), é apontado tanto por Leila Míccolis quanto por MacRae como o grupo de maior atuação e sobrevida nos anos oitenta.

Entretanto, cabe ressaltar que diferentes vetores implicam em diferentes formas de marginalização. Desta forma, a discriminação torna-se ainda mais incisiva quando a mulher também está marcada pelo estigma de raça. Neste caso, seu grau de invisibilidade/marginalidade torna-se ainda mais contundente. Fator que pode explicar o número escasso de mulheres negras nos diferentes grupos, como atestam MacRae e Míccolis. Todavia, nos anos oitenta, por

1 Todavia, uma pesquisa na Internet comprova a persistência da prática de formação de grupos homossexuais mistos como Etcetera e tal (1991) e Atobá (1985), por exemplo, nos anos noventa.

2 Apesar da Igreja Católica ter perdido muito de seu poder, não se pode negar sua influência na hora da discussão de questões polêmicas como o aborto (até hoje proibido no Brasil, apesar das campanhas). Além disso, sua atuação junto aos grupos feministas para a obtenção da anistia política no final dos anos setenta foi decisiva. 
sentirem-se acuadas ao serem acusadas de traírem os interesses de "sua comunidade" tanto por grupos negros quando privilegiavam a questão da sexualidade, quanto pelos grupos feministas ao quererem trazer para a pauta de discussão a questão de raça, essas mulheres foram aos poucos formando seus próprios grupos na busca por um espaço de onde pudessem lutar por posicionamentos políticos próprios.

Assim, a forte homofobia existente na sociedade brasileira tem feito com que uma grande maioria de mulheres lésbicas (não importando a raça ou a classe social) ainda prefira permanecer anônima por medo das consequiências de uma maior exposição pública. Muitas confessam que se sentem compelidas a manter uma aparência de "normalidade" nos locais de trabalho por medo de perder o emprego. Mas o que ocasiona esse forte sentimento de homofobia? Como explicar a reação contrária do público a reportagens e novelas que tentam tratar dessa temática de forma mais "positiva"? Sem querer aprofundar a discussão, pode-se explicar a origem desse sentimento pela forma como se estrutura a sociedade brasileira. Para ser mais clara, a família é percebida como a célula básica sobre a qual se estruturam as relações entre os indivíduos. Assim sendo, à mulher está reservado o papel de mãe e esposa, ou seja, esta é definida a partir de seu papel de reprodutora. ${ }^{3}$ Desse modo, qualquer mulher que tente fugir a esse princípio básico torna-se vitima de um violento processo de marginalização.

Por isso, teóricas como Judith Butler alertam sobre a importância em acrescentar sempre uma prática política ao nosso dia-a-dia. Uma prática que tenha como mola propulsora o constante questionamento das categorias e significados que procuram delimitar a forma como os indivíduos percebem a si próprios e a sociedade em que se inserem. Trata-se, na verdade, de uma forma de posicionamento que objetiva impedir a perpetuação de ideologias e crenças que impregnam o dia-a-dia das pessoas e que as fazem ver as relações sociais (que se baseiam numa dinâmica entre dominador e subordinado) como parte de uma ordem natural, numa dinâmica que persiste em manter determinados segmentos da população marginalizados.

Trata-se, na verdade, segundo Butler, de um processo que se baseia na imposição de paradigmas que obedecem a uma dinâmica marcada por uma estrutura dualística que delimita a esfera da exclusão e da inclusão, ou seja, o espaço do inteligível. Para tanto, observa-se uma proliferação de discursos que

3 Marilena Chaui (1988) em seu cstudo sobre a sexualidade feminina comprova que está proibida à mulher qualquer atividade sexual que não tenha como princípio básico a reprodução, uma vez que "o sexo (é permitido) apenas sob o prisma da reprodução da espécie, ou como função biológica procriadora". 
BEZERRA, K. C. Renata Pallottini: uma poćtica cm luta...

procuram delinear e delimitar a percepção do corpo através da veiculação de modelos fantasmáticos que, tornando-se elos de uma cadeia de significação, impelem o sujeito a um processo identificatório que se caracteriza por obedecer a uma dinâmica reiterativa e restritiva. ${ }^{4}$ Isto implica em dizer que o processo para a materialização do corpo, ou seja, seu ingresso no domínio do simbólico, estrutura-se a partir do repúdio a certas identificações e desejos. Um processo que, ao restringir as possibilidades de circulação de certos significados, vai implicar na dificuldade encontrada por diferentes pessoas em articular determinadas formas de desejo, como se verá em alguns poemas de Renata Pallottini.

Renata Pallottini nasceu em 20 de janeiro de 1931 na cidade de São Paulo, graduou-se em Filosofia Pura (1951) e Direito (1953), exercendo a advocacia por dez anos. Autora e tradutora muitas vezes premiada, escreve poesia, dramaturgia, ensaio, ficção, teoria de teatro, seriados para a televisão, literatura infantil e adaptações para o teatro. Publicou seu primeiro livro de poesia, Acalanto, em 1952 - impresso na gráfica da família. Nos anos oitenta, publicou os livros de poesia Cantar meu povo (1980), Cerejas, meu amor... (1982), Ao inventor das aves (1985), Mercado da paz (1988) e Esse vinho vadio (1988).

Mulher combativa, apesar de ter tido poemas e uma peça teatral censuradas, Renata Pallottini participou em 1979 de uma semana de protestos contra a ditadura militar no Teatro Municipal de São Paulo, tendo, inclusive, ajudado a organizar e participado sistematicamente da leitura de poesias em praças públicas. Todavia, seu lado combativo pode ser percebido em outras esferas de sua vida. Em entrevista concedida a Denira Rosário, Renata Pallottini confessa que, apesar de ter tido um avô italiano anarquista que a livrou de uma formação religiosa tradicional, ela não conseguiu ficar totalmente imune ao moralismo e ao preconceito da sociedade como um todo. Relata, então, que o fato de ter vivenciado décadas em que a mulher era percebida e valorizada a partir de seu papel de mãe e esposa, fez com que, com a eclosão da questão feminina no final da década de sessenta no Brasil, rejeitasse por muitos anos qualquer atividade que estivesse intimamente relacionada com os papéis femininos tradicionais; confessando, então, que só veio a aprender a cozinhar (e bem) anos mais tarde.

4 O grande número de reportagens preocupadas em traçar o novo perfil da mulher "moderna" em revistas e jornais publicados nos anos oitenta comprova a tese defendida por Michel Foucault que aponta a proliferação de discursos como um mecanismo regulador dos desejos dos indivíduos. 
Aqui, faz-se necessário abrir um parênteses, uma vez que dados como esse deixam patente o caráter conflituoso com que muitas mulheres confrontam as coisas da casa que precisam ser despidas de seu significado tradicional - o lugar e as atividades próprias das mulheres - para que possam ser reassumidas como atividades próprias e comuns a qualquer ser humano. Logo, como se pode verificar a partir do depoimento de Pallottini, a questão principal não se concentra em quem lava ou não a louça, ou mesmo em quem cozinha, mas na observância dos significados atribuídos a estas tarefas. Desse modo, a simples recusa das mulheres em desempenharem certas atividades, torna-se circunstancial se não se colocar em questionamento o mecanismo discursivo - falocentrismo - que teima em atribuir significados diferentes às tarefas desempenhadas por homens e mulheres. ${ }^{5}$

Fechado o parênteses, em termos de sua escrita, o que se observa é que esta também vai estar marcada por um posicionamento questionador e combativo. Em muitos de seus poemas prepondera uma crítica mordaz ao papel delimitado à mulher como transparece na forma como se refere às mulheres de sua família que "usaram cadeias de ouro? ("correntes", como se diz?). Correntes. / De ouro" (Pallottini, 1995, p. 290; 5-7). A crítica torna-se visível pela forma como o poema joga com o significado das palavras "cadeia" e "corrente", uma vez que ambas além de significarem cadeia de metal, correntes de anéis, também significam grilhão. Além do mais, a palavra "cadeia" também possui o significado de cativeiro, casa de detenção. Todavia, a intenção de jogar com o duplo significado das palavras fica mais evidente pela forma como estrutura os versos, pois ela não só separa o vocábulo "corrente" de seu adjunto adnominal por um ponto, provocando uma interrupção abrupta, mas desloca-o para o final do verso seguinte, obrigando o leitor a uma pausa ainda mais longa que reforça a ambigüidade desses versos e a ironia pois as "correntes" são feitas "de ouro".

Entretanto, sua crítica torna-se mais contundente nos versos que se seguem pela forma como suas ascendentes, descritas como mulheres que foram "trazidas", "transportadas" - a voz passiva realçando a passividade, percebem sua vida sexual:

Como a receita do pão era a receita da cama

5 É importante observar como, nos discursos que defendem uma divisão mais igualitária das tarefas com a casa e na educação dos filhos, o homem é normalmente conclamado a "ajudar", "colaborar" com a mulher. 
deitar-se e depois levantar-se

coisa imutável (Pallottini, 1995, p. 290; 41-44).

Aqui, é importante observar que a comparação não é feita ao pão (alimento básico e sacro presente na ceia do Senhor e que na sagração da missa significa o corpo de Deus), mas à receita do pão, ou seja, à sua forma de confecção que obedece a passos sistemáticos e precisos. Desse modo, o símile serve para caracterizar a forma mecânica, banal e imutável com que estas mulheres percebem o ato sexual. Além disso, ao contrário do que normalmente acontece na escrita masculina, o poema inverte os padrões ao caracterizar os maridos como um todo sem distinção - "Como um homem outro homem"(Pallottini, 1995, p. 290; 45), enquanto que atribui às mulheres uma singularidade baseada na peculiaridade de suas falas, ou seja, na forma saudosa e singular como cada uma falava do mundo de onde foram trazidas.

Entretanto, apesar do posicionamento questionador quanto aos valores tradicionais, seu senso crítico faz com que ela se interponha não só a um radicalismo presente no discurso feminista, mas também a um clima de maior liberdade sexual presente nos anos setenta. Por isso, em "Elogio da virgindade"(Pallottini, 1995, p. 310), a voz poética ao mesmo tempo que contesta um discurso tradicional que tem atribuído tanto valor a uma simples membrana "NÃO, NÃOÉ uma jóia pela qual se paga [...] Também não é a marca sem a qual tudo / perde a legitimidade e o valor consequiente" (Pallottini, 1995, p. 310; 1, 5-6), rejeita uma postura mais moderna que banaliza a relação sexual. Assim, consciente da importância da vivência sexual na vida dos indivíduos, adverte sobre o valor da primeira relação sexual que não deve acontecer "no banco posterior de um automóvel"(Pallottini, 1995, p. 310; 23) por ser um momento especial, pois é o minuto de descoberta do que a vida guarda.

Mas sua postura crítica não pára por aí. Em outros poemas, há uma rejeição à tentativa de imposição de uma imagem cristalizada e marmorizada da mulher presente $\mathrm{em}$ tantos discursos. Por isso, a voz poética continuamente avisa: "Mudei / estou mudando"(Pallottini, 1995, p. 316; 15-16) ou "(Qualquer coisa mudava e sempre muda / enquanto o ser se faz / passo por passo)" (Pallottini, 1995, p. 350; 34-35) em versos em que o uso do verbo mudar no gerúndio acompanhado do verbo estar ou o seu uso no pretérito imperfeito do indicativo enfatizam a idéia de continuidade, ou seja, a existência de um fato em contínua realização, em processo de mutação. Já o uso da locução adverbial - "passo por passo" - reforça a idéia de uma mudança que acontece lentamente e cuja intensidade é marcada pela repetição do fonema oclusivo sonoro $/ \mathrm{p} /$. 
Já em outros poemas aflora a crítica à forma como a mulher é valorizada por discursos que a percebem enquanto um objeto a ser apreciado. Em "Poema despeitado para Bruna Lombardi"(Pallottini, 1995, p. 304-305), por exemplo, a voz poética confessa de forma sarcástica sua inveja de Bruna Lombardi - uma mulher que preenche o padrão de beleza por ser loura, magra, sensual e ter olhos azuis, enfim, um rosto sempre presente nas capas de revista. Declara, então:

\author{
Ser bom poeta? À merda. \\ Tudo isso é uma grande balela. \\ Queria mesmo é ser colorida, \\ ser muito bela, ser muito bela (Pallottini, 1995, p. 304; 10-13).
}

No poema, a voz poética critica, consequentemente, o processo de objetificação sexual a que está sujeita a mulher por viver numa sociedade em que o imperativo de beleza está intimamente relacionado ao fator de atração sexual.

Todavia, seu olhar perscrutador não está restrito à mulher. Muitos de seus poemas promovem um corte transversal na sociedade, mostrando suas mazelas e injustiças. Assim, em "A pobre gente"(Pallottini, 1995, p. 274), a voz poética procura compreender e falar da pobre gente que "Não são / não foram nunca / havidos com justiça"(Pallottini, 1995, p. 274; 5-7) onde o uso do verbo no presente e no passado $\mathrm{e} o$ acúmulo de advérbios negativos apontam para a longa persistência dessa situação. Declara, então, em "Cantar meu povo" (Pallottini, 1995, p. 261-63), que seus poemas dirigem-se a

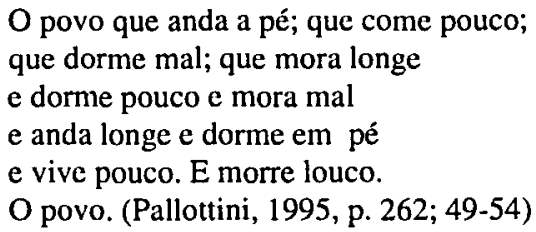

Nesse poema, o fato de separar as orações subordinadas por ponto e vírgula obriga o leitor a uma leitura mais pausada que o leva a refletir sobre cada segmento. Além disso, os três versos que se seguem são formados por orações coordenadas aditivas, sendo que a ausência de vírgulas para separá-las marca a simultaneidade entre os elementos que compõem a vida do povo. Outro ponto 
que se deve destacar é que a repetição monótona dos verbos andar, morar e dormir atesta o teor rotineiro de suas vidas assim como o uso repetitivo dos advérbios de modo mal e pouco evidenciam a escassez em suas existências. Finalmente, ao separar "E morre louco" da seqüência, transformando-a em uma oração à parte, a voz poética coloca em evidência o processo de loucura a que o indivíduo do povo está sujeito no final de sua vida devido à cansativa rotina/sequiência que constitui seu dia-a-dia.

Nesse sentido, nos dez anos em que praticou advocacia, Renata Pallottini confessa ter tido um contato mais direto com o sofrimento do povo. Uma vivência que vai transparecer em poemas cujas temáticas tratam, por exemplo, da violência contra crianças como em "Depoimento cruel n. 2 (Defloramento precoce)" (Pallottini, 1995, p. 307-308) que retrata de forma fria o defloramento de uma menor de idade e a forma preconceituosa como as vítimas são tratadas pela polícia:

FOI TEU tio quem te fez isso?

- Não, foi meu irmão.

- Você gostou?

- Senhor?

- Você gostou?

- Depois ele me levou

a comer pizza. Eu gostei.

Como pode ser percebido nos poemas analisados até aqui, seus versos estão sempre marcados por um posicionamento crítico que procura problematizar valores e comportamentos presentes no dia-a-dia das pessoas. Contudo, em alguns poemas, a voz poética mostra-se menos direta, valendo-se de uma linguagem mais ambígua em que prepondera a insinuação, a dissimulação. Trata-se de poemas em que a voz poética queixa-se quanto à impossibilidade de vivenciar o prazer plenamente, vendo-se obrigada a mantê-lo encoberto. No livro Cerejas, meu amor... (1982), o primeiro poema, que dá o nome ao livro, marca a presença do erótico em sua poesia:

CEREJAS, meu amor, mas no teu corpo. Que elas te percorram por redondas. 


\author{
E rolem para onde \\ possa eu buscá-las \\ lá onde a vida começa \\ e onde acaba \\ e onde todas as fomes \\ se concentram \\ no vermelho da carne \\ das cerejas... (Pallottini, 1995, p. 287)
}

No poema, no plano fonético percebe-se que, enquanto a constante repetição do fonema vibrante / $\mathrm{r} / \mathrm{em}$ vocábulos como "percorram", "redondas" e "rolem" contribui para a idéia do rolar, do deslizar das cerejas pelo corpo da pessoa amada; a presença dos sons nasais (sons velados) sugere a lentidão e doçura que fazem parte deste rolar, contribuindo para a instauração de uma atmosfera de erotismo. Some-se a isso a caracterização da carne por sua cor vermelha - cor que traz a idéia de fogo, paixão, a repetição enfática do "(e) onde" demarcando um lá que é sugerido como a fonte de vida e morte e a origem de todas as fomes e, finalmente, o deslocamento do adjunto adnominal "das cerejas" para o último verso, seguido de reticências; elementos que contribuem para a instauração de um jogo de insinuação e burla.

Em “O meu prazer"(Pallottini, 1995, p. 292), terceiro poema deste mesmo livro, a interdição ao prazer evidencia-se pelo seu alijamento ao espaço do sonho. O poema é construído por imagens em que os adjetivos contribuem para evidenciar a existência de uma atmosfera de interdição e ocultamento que tem se perpetuado através dos tempos, uma vez que se tratam de "almofadas escuras" por estarem guardadas, "séculos mornos" e uma "alegria represada". Não é por acaso que o corpo, comparado a uma ponte úmida, vai se aproximando pouco a pouco ("de escada a escada") num encontro que ocorre numa "penumbra secreta", ou seja, num local escondido e de difícil visibilidade; sendo que aqui, o deslocamento do adjetivo "secreta" para o final do verso seguinte reforça ainda mais a necessidade de manter esse sentimento oculto. Mas estes versos revelam muito mais. Primeiro, o corpo, como uma ponte, é percebido como o elemento que possibilita a ligação entre esses dois indivíduos. Além disso, o fato deste corpo/ponte estar oleoso/úmido significa percebê-lo como algo escorregadio, suave, macio, doce - uma imagem que contribui para o teor erótico do poema.

Depara-se, por conseguinte, com um momento de espera em que prepondera o desejo de que, como a voz poética adverte, "uma alegria represada atinja a cor / do fogo". Todavia, o desejo de plenitude ainda está restrito ao espaço da 
BEZERRA, K. C. Renata Pallottini: uma poćtica cm luta...

madrugada - um intervalo de tempo que corresponde às últimas horas da noite, antes do amanhecer, ou seja, um momento de escuridão e penumbra antes da vinda da luz do dia como alerta a voz poética:

De tanto eu te sonhar formou-se a madrugada

que nos envolve num fervor exausto.

Estamos prestes

a descobrir o infinito da carne

no infinito da alma. (Pallottini, 1995, p. 292; 29-31,34-36)

Nesse sentido, a restrição desse momento de prazer ao espaço da madrugada pode ser melhor compreendida quando se tem em mente que o adjetivo prestes tanto pode significar estar pronto, preparado, como pode remeter para algo que está a ponto de acontecer, ou seja, um tempo ainda no futuro, embora bem próximo e imediatamente posterior ao atual. Além disso, o adjetivo exausto - completamente esgotado, extenuado até a última gota - alude para a questão do cansaço que sente em decorrência do longo tempo de repressão e ocultamento do desejo que a domina.

No sétimo poema deste livro, "Neste áureo outono..."(Pallottini, 1995, p. 294-95), o tom de resignação da voz poética pode ser percebido pela repetição de "Deixa". Neste poema, o constante uso de frases entrecortadas e reticências enfatiza a percepção da interdição a uma completude assim como seu temor em lutar e falar sobre seu desejo:

Alguém sabe por que me foi negado o mar da plenitude e o vício da coragem. (Pallottini, 1995, p. 294-95; 44-46)

Nesse sentido, o uso do pronome demonstrativo neutro aquilo em “Ninguém saberá o que foi / aquilo que nós fizemos"(Pallottini, 1995, p. 294-95; 25-26) contribui para a construção de uma atmosfera de indefinição e ambigüidade. Não é por acaso que, apesar de caminharem "na avenida dos antigos preconceitos" onde, embora as luzes estejam verdes, a presença de musgo nas vitrines dificulta a visão, permitindo um certo encobrimento. Todavia, ao contrário dos poemas anteriores onde não se consegue detectar quem é o objeto 
do seu desejo, o uso do adjetivo "preciosas" serve de índice de que o poema refere-se ao desejo entre duas mulheres. Desejo impregnado por um sentimento de medo, tristeza e arrependimento, como pode ser percebido não só pela certeza de que o momento passou, como transparece nos seguintes versos: "se eu não te amei foi porque / não tinha tempo...)" (Pallottini, 1995, p. 294, 17-18) e "Será que a vida caminhou, / não tem mais jeito..." (Pallottini, 1995, p. 295, 42-43), mas também por causar um certo incômodo, mal-estar:

\author{
Cada vez mais pesa o momento frio \\ Em que a roupa descansa ao pé da cama \\ E não se tem mais nada sobre a pele \\ A não ser o desejo, louco e leve...
}

Sentimentos, na verdade, que ajudam a entender os versos que fecham o poema:

\author{
e esse macio \\ maciço entendimento a cobrir com \\ seu corpo \\ toda a estação uníssona \\ do nosso áureo outono... (Pallottini, 1995, p. 295; 55-59)
}

Aqui, o jogo que se instaura através da aliteração entre macio e maciço, palavras com significados antitéticos dispostas em versos diferentes, constituise a partir de uma dinâmica que procura mostrar a relação tencionada entre os dois vocábulos. Nesse sentido, o uso desses dois adjetivos para caracterizar o entendimento sobre a impossibilidade de ter prazer e falar sobre essa forma de desejo provoca a transmutação desse entendimento (algo abstrato) num corpo sólido que encobre com seu som uníssono (som igual, sem alteração e, por isso, monótono) toda a estação, atestando para a impossibilidade de lutar. Além disso, a presença do fonema alveolar/s/ (som sibilante) nas duas palavras traz a idéia de algo que é sussurrado por medo de que outros ouçam. Finalmente, a escolha do adjetivo áureo para caracterizar o outono (período que antecede o inverno, simbolizando decadência, ocaso) pode ter diferentes conotações. Primeiro, pode caracterizar um momento de encontro que, apesar de doloroso, transforma esta estação em um período especial na vida de uma pessoa. Por outro lado, quando 
lhe é atribuído um teor sarcástico, serve para denunciar preconceitos que a impedem de vivenciar de forma plena o seu desejo "louco e leve".

Desse modo, como fica claro tendo em vista os poemas acima analisados, a mulher que aflora de seus versos mostra-se um ser complexo que foge completamente à forma como a mulher tem sido normalmente percebida por diferentes discursos. Depara-se, na verdade, com um sujeito consciente da importância de lutar contra papéis e valores tradicionais e modernos que têm cerceado o seu caminhar, um ser fragmentado por um sentimento de repulsa $\mathrm{c}$ atração pelos modelos veiculados por um discurso dominante, um ser que se solidariza com seu povo pelo vínculo de opressão que os une, celebrando, ao mesmo tempo, a força que o(s) faz sobreviver a todas as vicissitudes e que, no entanto, ainda enredado pelo temor em vivenciar sua sexualidade de forma plena, sofre.

Todavia, é importante ter em mente que, embora o desejo homocrótico seja articulado de forma camuflada e tensionada, somente o fato do desejo e do prazer entre duas mulheres ser articulado como uma possibilidade na esfera do erótico pode impulsionar a reformulação do simbólico por guiar-se por uma cconomia que foge à estruturação binária e oposicionista. Em outras palavras, tendo-se por base os pressupostos traçados por Freud $\mathrm{c}$ retrabalhados por Butler, se o ego constitui-se a partir de uma projeção calcada nas possibilidades morfológicas inteligíveis orquestradas por normas regulatórias, a articulação de novas possibilidades de identificação e de percepção do desejo pode propiciar a problematização e maior flexibilidade do que é tido como inteligível, provocando, consequentemente, uma maior malcabilidade no domínio do simbólico.

Em síntese, é fácil perceber o quanto a forma discriminatória como a socicdade brasileira está estruturada interferc na forma como o indivíduo percebe a si próprio. Em outras palavras, a massiva veiculação de discursos normatizadores nas diferentes instâncias e momentos da vida do indivíduo, ou seja, no espaço da escola, da família, do mercado de trabalho e na distribuição de benefícios, tem propiciado a criação de espaços de exclusão que impedem os indivíduos de vivenciarem diferentes formas de prazer. Não é por acaso que a leitura de jornais e revistas assim como os depoimentos de pessoas de diferentes setores da população atestam para a dificuldade em colocar em questionamento "verdades" e "certezas" que fazem parte de um "senso comum" que persiste em delimitar as formas de desejo. Não se pode negar, no entanto, que os significados das categorias de gênero, sexualidade, classe e raça, por exemplo, têm sofrido modificações através dos tempos em decorrência de diferentes fatores; no entanto, deve-se ter cuidado, pois a discriminação muitas vezes ainda se encontra presente nestes novos conceitos, apesar de conquistas 
e de pequenos avanços. Por isso a importância da existência de vozes como a de Renata Pallottini que, embora de forma tensionada, procuram articular novas formas de desejo. Uma tensão, na verdade, que se torna significativa pois serve de indício do grau de violência a que estão sujeitos os indivíduos que almejam construir novas formas de ser.

\section{RESUMO}

O lento processo de abertura política que se inicia nos meados dos anos setenta no Brasil permite que diferentes grupos retomem seus movimentos reivindicatórios. Dentre estes, organizam-se grupos que se voltam especificamente para a questão da homossexualidade masculina e feminina. Todavia, a forte homofobia que ainda impera na sociedade impede que seus posicionamentos ganhem uma maior visibilidade $e$ legitimidade. Uma barreira que tem dificultado a articulação do desejo homoerótico por parte de muitos. Nesse sentido, o presente trabalho pretende se voltar para o estudo de alguns poemas produzidos por Renata Pallotini nos anos oitenta. Poemas que tratam, de forma ambígua, uma linguagem sugestiva do desejo homoerótico.

Palavras-chave: desejo homoerótico, ambiguidade, interdição.

\section{ABSTRACT}

As the slow and long demilitarization process begins in the mid 1970s in Brazil, various social groups resume their struggle for more equality. Among them are those groups distinctively concerned with the issue of homosexuality. Yet, the strong homophobia still present in Brazil not only prevents their views to become more visible, it also makes the expression of their homoerotic desire more difficult. In this article, we intend to examine three poems written by Renata Pallottini in the 1980s in Brazil which, by means of a play with ambiguity, attempt to deal with such an aspiration.

Key words: homoerotic desire, ambiguity, interdiction. 


\section{REFERÊNCIAS}

BASSANEZA, Carla. Revistas femininas e o ideal de felicidade conjugal (1945-1964). Pagu, p. 111-148.

BUTLER, Judith. The pleasure of repetition. In: GLICK, Robert A.; BONE, Stanley (Eds.). Pleasure beyond the pleasure principle. New Haven: Yale University Press, 1990. p. 259-275.

Imitation and gender insubordination. In: ABELOVE, Michèle; BARALE, Aina; HALPERIN, David M. (Eds.). The lesbian and gay studies reader. New York: Routledge, 1993. p. 307-320.

CHAUí, Marilena. Repressão sexual: essa nossa (des)conhecida 11. ed. São Paulo: Brasiliense, 1988.

FERREIRA, Aurélio Buarque de Holanda. Novo Aurélio Século XXI: o dicionário da língua portuguesa. 3.ed. ver. e aum. Rio de Janeiro: Nova Fronteira, 1999.

FOUCAULT, Michel. History of sexuality. v. 1. New York: Vintage Books, 1980.

MacRAE, Edward. A construção da igualdade: identidade sexual e política no Brasil da "abertura". Campinas: Editora da UNICAMP, 1990.

MÍCCOLIS, Leila. E-mail para a autora. 30 de setembro de 1998.

PALLOTTINI, Renata. Obra poética. São Paulo: Hucitec, 1995.

. Renata Pallottini. In: ROSÁRIO, Denira (Ed.). Palavra de mulher: coletânea de entrevistas e antologia poética. Rio de Janeiro: José Olympio, 1989. p. 150-158. Entrevista. 